\title{
Development and psychometric properties of the HBM- based Substance Abuse Prevention Questionnaire (HBM-SAPQA) among Afghanian students
}

Kanali Mohammadi

Tarbiat Modares University Faculty of Agriculture

Sedigheh sadat Tavafian ( $\square$ tavafian@modares.ac.ir)

Tarbiat Modares University https://orcid.org/0000-0002-6161-0801

Mahmoud Tavousi

Iranian Institute for Health Sciences Research

Research article

Keywords:

Posted Date: May 27th, 2020

DOI: https://doi.org/10.21203/rs.3.rs-30141/v1

License: (c) (i) This work is licensed under a Creative Commons Attribution 4.0 International License.

Read Full License 
1 Development and psychometric properties of the HBM- based Substance Abuse

2 Prevention Questionnaire (HBM-SAPQA) among Afghanian students

3

$4 \quad$ Kanali Mohammadi ${ }^{1}$, Sedigheh Sadat Tavafian ${ }^{2 *}$, Mahmoud Tavousi ${ }^{3}$

5 1- Department of Health Education and Health Promotion, Faculty of Medical Sciences, Tarbiat Modares

6 University, Tehran, Iran.

7 2-Department of Health Education and Health Promotion, Faculty of Medical Sciences, Tarbiat Modares

8 University, Tehran, Iran

9 3- Health Metrics Research Center, Iranian Institute for Health Sciences Research, ACECR, Tehran, Iran.

10

11 Authors' e-mails:

12 KHM: khanali.mohammadi@modares.ac.ir

13 SST: tavafian@modares.ac.ir

14 MT: tavousi@acecr.ac.ir

15

16 * Corresponding author

17 


\section{Abstract}

\section{Background}

20 In Afghanistan, adolescents and young people are the most important at risk groups for

21 substance abuse. Considering the importance of model-based interventions, this study aims to

22 design and validate a questionnaire based on the Health Belief Model (HBM) for assessing the

23 beliefs of Afghan students regarding substance abuse prevention behavior.

\section{Methods}

25 This study was conducted in two stages. Firstly, the items of the questionnaire were designed by 26 conducting a combined documentary literature review and qualitative study. In the next step, its

27 psychometric properties were evaluated through qualitative and quantitative formal validity 28 (calculation of impact score), qualitative and quantitative content validity - Content Validity 29 Ratio (CVR) and Content Validity Index (CVI)- and structural validity through Factor 30 Explanatory Analysis (FEA). Finally, consistency compatibility through Cronbach's alpha as 31 well as reliability (internal correlation) test re-test were assessed. To above steps, the SPSS 32 version 18 was applied.

\section{Results}

3474 items were obtained for the questionnaire by performing a qualitative study and using 35 existing scientific sources for literature review. In the study of formal validity of quantitative 36 items, the effect coefficient of all above 1.5 was calculated. The CVR of each item was more 37 than 0.8 (mean 0.93 ), and their CVI was more than 0.79 . In this stage, 12 items related to cues to 38 action hanged to 1 item with 12 options so all 63 remained items were retained in the 39 questionnaire. In FEA 40 items related to main constructs of HBM were assessed by which, by 40 eliminating 2 items, structural validity was confirmed for 38 items in 5 factors and covering 41 about $40 \%$ of the variance for EFA 408 students with average age of 23 years old were assessed. In the internal compatibility process, the acceptable values of Cronbach's alpha 

of the instrument.

\section{Conclusion}

46 The HBM-SAPQA tool obtained the acceptable validity/reliability to apply the beliefs of 47 Afghan students regarding substance abuse preventive behavior. Although the result of this study showed, this questionnaire has good validity and reliability, but this result should be 49 confirmed in future studies.

50

\section{$51 \quad$ Key words}

52 Psychometrics properties, Questionnaire, Health Belief Model, Substance abuse prevention, 53 Students, Afghanistan 


\section{Background}

Most of the reports on substances abuse especially among youth aged 18-25 year olds, with gradually annual increasing rate, back to modern times [1]. A significant number of this age group will study in colleges and universities [2], where they involve with a complex factors of new academic life, new relationships with their university friends and form their new social support [3]. It has been argued that the main factors of students' tendency to using psychoactive substances have been failure to meet emotional needs, sense of better functioning, taking pleasure and management of their emotions $[4,5]$.

Increased substance abuse among university student populations is an important public health issue which, wastes a lot of human and economic capital in a very destructive form [1]. Among students, in addition to loss of academic achievement, substances abuse can could be resulted in many other immediate and long-term subsequences like engaging in risky sexual behaviors, violent behavior and other kinds of physical and psychosocial health problem [6,7] as well as excess youth morbidity and mortality $[8,9]$.

According to statements of experts and governmental principals in Afghanistan, addiction rate is increasing in this country. These experts verified that, in Afghanistan - as the world's largest producer of opium - factors like cheap substances, easily substance available, made addiction issue with more risk and higher prevalence. In other hand, lake of economic, social and security development in Afghanistan, is a major factor for more prevalent addiction especially among youths that are high risk group of Afghan population. Consistently previous study revealed that low educational and low socio-economic status of the societies, and also low cost and easy availability of substance as well as low academic achievement and low social support were associated with substance use among youth [10].

Harm from substance misuse among university students is a pertinent public health issue, so existed evidences recommend that interventional approaches that could improve the university 
environment surrounding students may have better potential to impact on long-term substance use harm reductions in students $[1,11]$. However, these studies verified in spite of this fact that universities are ideally place to be intervened to reduce illicit substance misuse, there are few interventions focused on illicit substance misuse in these institutions [11]. In the recent years, the fever of substances and psychoactive substances consumption has grown among different social classes of the country; this issue as a cultural and social damage will threaten the physical and mental health of the society $[5,7]$. Substance addiction is known as a health, therapeutic, and social problem of the recent century.

Although, recent studies have shown that young people have little resistance against substances, but the HBM based studies verified that youths have the ability to perceive the risk and adverse outcomes of using substances [12]. Health Belief Model has a proper pattern and structures of factors like perceived severity, perceived sensitivity, perceived benefits, perceived barriers and perceived self-efficacy appropriate to students' beliefs conditions [13].

Furthermore, youths' perceived benefit/barrier and also their awareness of factors related to prevention of substance use can significantly promote their preventive behaviors. 6 It has been discussed that youths often have a weak perception of the risks to which they may expose themselves when they consume substance that may stem from the immediate pleasure or stress relief [14]. According existed evidence, for preventing substance abuse, an appropriate prevention strategy based on culture and needs of the audience should be designed [12]. Thus, one of the most important things that cause appropriate need assessment of audiences is an accurate, valid and appropriate tool to assess students' awareness and beliefs regarding addiction preventive behaviors.

As substance use among Afghanian youths has been increasing, and on the other hand, little is known about the correlates of the problem in this population, Identification of the correlates is required for development of preventive approaches that aim to reduce or eliminate risk. 


\section{Methods}

\section{The conceptual framework \& Item generation}

113 To develop and valid this questionnaire, a combined qualitative and quantitative study were 114 conducted. At first, to compile the items of the questionnaire, based on library studies and a 115 review of scientific literature, the necessary information was collected to design the items. This 116 information was then completed through interviews with students and also experts who were 117 working at the Ministry of Health, and Ministry of Counter Narcotics of Afghanistan, as well as 118 additional intelligence personnel.

Accordingly, to design this appropriate preventive intervention exploring the beliefs of students regarding addiction preventive behaviors is strongly needed. Thus, due to the lack of any tools in Afghanistan, this study aimed to design an appropriate HBM- based substance abuse preventive behavior tools and evaluate its psychometric properties to apply for measuring subjective beliefs of the Afghan students regarding addiction preventive behavior.

For doing interviews, the interviewees were asked several descriptive questions about "The reasons and related factors for the increased prevalence of substance use in Afghanistan, procedures and educational strategies to reduce substance use in students."

The collected information was then analyzed using MAXQDA11 software and the questionnaire items were designed according to the extracted codes. The items in the questionnaire were designed taking into account cultural and social considerations and the level of the socio cultural characteristics in society of Ghazni city -as the 2end populated city in Afghanistan after Kabul. Furthermore, the interview questions were based on HBM constructive including perceived sensitivity, perceived severity, perceived benefits/ barriers and perceived self-efficacy of the students regarding addiction preventive behaviors. In addition to the above items, in which the main structures of the HBM were considered, a number of items were asked to measure the 


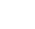

knowledge of students regarding substance prevention behaviors, cues to action for this behavior, intention to doing substance prevention behaviors and also questions to examine demographic characteristics.

\section{Content validity}

In the content validity review approaches, the Content Validity Ratio (CVR) and the Content Validity Index (CVI) were calculated using 10 experts and scholars. The values obtained in CVR were calculated and analyzed using Lawshe table and the relevant formula. To calculate the CVI, values above 0.79 were accepted. Moreover, formal narration was done through qualitatively and quantitatively (impact score) via obtaining students' opinions.

\section{Construct validity}

Exploratory Factor Analysis (EFA) was used to investigate structural validity. In this analysis, to test the adequacy of sample size for factor analysis, KMO 'test was used. Prior to the analysis, the main components of the data to be fitted for factor analysis, were evaluated. Analysis (EFA) with varimax rotation and internal consistency respectively. The Kaiser-MeyerOlkin (KMO) and Bartlett's Test of Sphericity were used to determine the appropriateness of the sample for factor analysis [15-16]. Eigenvalues above 1 were considered appropriate to verify the number of possible underlying factors. In this analysis, to test the adequacy of sample size for factor analysis, $\mathrm{KMO}$ 'test was used. Prior to the analysis, the main components of the data to be fitted for factor analysis, were evaluated. In the next step, Exploratory Factor Analysis (EFA) was used to investigate structural validity.

\section{Reliability}

Consistency of the questionnaire was approved through Cronbach's alpha calculation in which 
information was obtained from 30 students. Cronbach's alpha values for all items and each factors were measured. The Cronbach's alpha coefficient (acceptable level of 0.7) for each dimension and the whole scale was calculated to examine internal consistency [17]. To analyze the above steps, version 18 SPSS software was used.

\section{Results}

Based on qualitative phase of this study, a questionnaire consisting of 74 items including 17 items of knowledge, 12 item of cues to action and 5 items of preventive behavioral intention and 40 items related to main constructs of HBM were obtained.

All items of main constructs of HBM were considered for the psychometric properties. In this regard, first of all, in order to check the validity of the content with a qualitative approach, issues such as following the right grammar, using appropriate words, placing the items in the right place, proper scoring and the time required to complete the tools were assessed from the perspective of experts and then all their viewpoints took into account.

After compiling the questionnaire items in the qualitative study, the opinions of experts with a qualitative approach in content validity and students' opinions with a qualitative approach in formal validity (correction of an item) were applied in the questionnaire.

\section{Content validity}

In CVI process based on experts' viewpoints, since the effect of all items was higher than 1.5, all items were retained and identified as suitable for further analysis. In the CVR, according to the Lawshe table, the calculated value for all items was more than 0.56 by which all items were maintained in the questionnaire (average was about 0.93 ). In the content validity index (CVI), all items in the questionnaire were retained according to values above 0.79 (approximately 0.91 ). Thus, in the CVR/CVI process and in formal validity (impact score), all 40 items met the 
relevant and necessity criteria and remained in the questionnaire.

\section{Factor structure}

To accomplish the construct validity through EFA, 408 students -of Khatam Al-Nabieen University- including 267 boys (65.4\%) and 141 girls (34.6\%) with an average age of 23 years participated in the study.

The rest 40 items regarding HBM constructs were considered for construct validity. In the next step, Exploratory Factor Analysis (EFA) was used to investigate structural validity.

During construct validity process, the KMO level of 0.737 confirmed the adequacy of sampling. The Quartet Bartlett Test also showed that the factor analysis was appropriate for identifying the structure of the factor model $(431 / 331, \mathrm{P}<0.001$ and $\mathrm{df}=703)$. At the end of the EFA, two items were removed from the questionnaire because of low loading. Thus, a questionnaire with 38 items in 5 factors and with covering about $40 \%$ of the variance showed an acceptable structural validity (Table 1$)$.

According EFA, eight items were set in perceived susceptibility category, 8 items in perceived severity, 9 items in perceived benefits, 9 items in perceived barriers, and 4 items in perceived self-efficacy. However, 2 items did not obtain acceptable loading and were omitted. Table 1 shows the instruments after EFA with 38 items in 5 factors.

These questions were measured based on 5-point Likert spectrum options which scored numerically and for all constructs by which the higher scores showed better conditions.

\section{Reliability}

The internal compatibility through Cronbach's alpha values for whole questionnaire was 0.826 and for each factors were as follows: 0.818 for perceived sensitivity, 0.819 for perceived severity, 0.801 for perceived benefit, 0.812 for perceived barrier, and 0.81 for perceived selfefficacy. 
206 The purpose of this study was to design and psychometric appraise the tool named HBM- based

207 Substance Abuse Prevention Questionnaire (HBM-SAPQA) to measure the beliefs of Afghanian

208 student's addiction preventive behaviors. In a previous study, the opinions and beliefs of

209 Spanish teenagers regarding tobacco and alcohol consumption were assessed through a

210 descriptive study in which a valid instrument was applied [14]. However, as there was no

211 cultural appropriated instrument to assess the beliefs of afghan students, this study was designed

212 to originate the instrument.

213 The primary items were originated and developed based on data from a qualitative study and

214 literature review on studies regarding addiction reasons, substance abuse and preventive

215 behaviors especially among university students. Furthermore, the statements for this instrument

216 were prepared through literature review based on characteristics and mechanism of HBM

217 function [13]. Furthermore, to obtain related and valid statement for the questionnaire, in

218 addition to students, experts who were involved with addiction prevention in Afghanestan at the

219 Afghan Ministry of Health, Ministry of Counter of Narcotics, as well as additional intelligence

220 personnel were interviewed.

221 It has been revealed that individuals, who experienced a problem, are the best ones to provide

222 input on factors, which might be effective [18]. In the investigation, we asked the experts about

223 the related factors, which might affect high prevalence of addiction among young people in

224 Afghanistan in the framework of HBM. According HBM constructs the experts and the students

225 were asked how subjectively the students assess themselves of being high risk to be involved

226 and how they perceive the severity of this problem. Moreover, they were asked how they

227 perceive the benefits and barriers of substance abuse preventive behaviors and how they are

228 confident to successfully perform healthy behaviors to prevent addiction problem [13].

229 In present study, to determine Content Validity Ratio and Content Validity Index, of HBM- 
SAPQA, the items obtained from the qualitative study and literature review, were presented to a number of experts, and their comments were considered so that some items were merged or changed verbally. However, the findings regarding both CVR and CVI showed all items obtained acceptable score. This rate of validity represent that this questionnaire included items that are related to and necessary for the studied issue. In consistent with this finding, the other study also obtained similar content validity for its' designed instrument [19]. school students in which the range of internal consistency was reported from 0.76 to 0.90 [20].

According construct validity in present study, the findings indicated that HBM-SAPQA has appropriate structural validity so that it encompasses five main constructs of HBM including perceived benefit, perceived barrier, perceived severity, perceived susceptibility and perceived self-efficacy. In fact, this instrument now could assess all main HBM constructs that are HBMdriven constructs. For instance, EFA revealed that HBM-SAPQA had satisfactory loading in five factors that is consistent with the main constructs of the original model [13]. Interestingly most participants completed the questionnaire without any hardness and they found it userfriendly. Indeed, the HBM-SAPQA is a multidimensional instrument containing a set of constructs that collectively could indicate beliefs of Afghan students for assessing their intention towards addiction preventive behaviors. These beliefs are very important in preventing addiction among different student's groups in Afghanistan. Without understanding such beliefs development of educational interventions almost is impossible.

Determining internal consistency of the HBM-SAPQA through Cronbach's alpha showed acceptable range from 0.71 to 0.82 for different constructs and 0.82 for all items that indicated good internal compatibility for all items.

This finding is in the line of previous study conducted in Iran that was about psychometric characteristics of a HBM-based questionnaire regarding substance dependence among high In the present study the reliability of the questionnaire was in the acceptable range. This means 
that this instrument has obtained enough clarity by which the answers to the questions is

256 reliable. In an existed study [19] the reliability of the smoking prevention questionnaire based

257 on the HBM for students was reported similar to present study.

258 Although this study had several strengths that were discussed above, like many other studies,

259 there are some limitations. The most important limitation was the fact that students responded to

260 the questionnaire through self-reporting and at their university, so this might have affected their

261 answers. Moreover, either addiction or beliefs are sensitive issues that speaking about them

262 might be hard and non-clear. In other hand, the students were selected from one university and

263 so this may interfere the representation of the study. Despite these limitations, the HBM- based

264 Substance Abuse Prevention Questionnaire among Afghan students had the optimal statistical

265 properties for five factors that is consistent with original HBM with 5 main constructs.

266 Additionally, this instruments; psychometric properties is supported by existed evidences.

267 Furthermore, this valid instrument has been made for the first time for a very low income

268 country which is severely involved in substance use

269

270 Abbreviations

271 HBM: Health Belief Model

272 SAPQA: Substance Abuse Prevention Questionnaire

273 CVR: Content Validity Ratio

274 CVI: Content Validity Index

275 EFA: Exploratory Factor Analysis

\section{Declrations}

278 Ethics approval and consent to participate 
279 The ethics committee of Tarbiat Modares University approved the study(ID:

280 IR.TMU.REC.1394.251, Date: February 4, 2016). . All participants signed the written consent 281 form.

282

283 Consent for publication

284 Not applicable.

285

286

Availability of data and materials

287

The data is available from the corresponding author upon reasonable request.

\section{Competing interests}

290 The authors declare that they have no competing interests.

\section{Funding}

293 The authors received no financial support for the research, authorship, and/or publication of this 294 article.

296 Authors 'contribution

297 KHM participated in all parts of the study; SST supervised the study; and MT was 298 advisor of the study and checked the data analysis. All authors participated in 299 writing and approving the manuscript.

\section{$300 \quad$ Acknowledgements}

301 We are grateful to all participants who made this study possible. 
1. Dick S, Whelan E, Davoren MP. et al. A systematic review of the effectiveness of digital interventions for illicit substance misuse harm reduction in third-level students. BMC Public Health 2019; 19: 1244.

2. Bennett TH, Holloway KR. Drug misuse Among University students in the UK: implications 308 for prevention. Substance Use \& Misuse 2014; 49(4): 448-55.

309 3. Awang MM, Kutty FM, Ahmad AR. Perceived social support and well being: first-year 310 student experience in university. International Education Studies 2014; 7(13): 261-270.

311 4. Rahimi Pordanjani S, Fallah Zadeh H, Mousavi M, Khazaei S, Sohrabivafa M, et al. 312 Prevalence and Reasons for Psychoactive Substances Use Among University Students of 313 Medical Sciences in Yazd, Iran. Iranian Journal of Psychiatry and Behavioral Sciences 2018 ; 314 12(1): e9384.

315 5. Pickover A, Yurasek A, Lejuez C, Murphy J. Emotion regulation predicts drug use among 316 college binge drinkers. Drug and Alcohol Dependence 2014; 140: e176.

317 6. Skidmore CR, Kaufman EA, Crowell SE. Substance use among college students. 318 Child and Adolescent Psychiatric Clinics 2016; 25(4): 735-53.

319 7. Palmer RS, McMahon TJ, Moreggi DI, Rounsaville BJ, Ball SA. College student drug use: 320 patterns, concerns, consequences, and interest in intervention. Journal 321 of College Student Development 2012; 53(1): 124-32.

322 8. Henderson, M, Nixon C, McKee MJ. et al. Poly-substance use and sexual risk behaviors: a cross-sectional comparison of adolescents in mainstream and alternative education settings. $B M C$ Public Health 2019; 19: 564 .

325 9- Park, S., Kim, Y. Prevalence, correlates, and associated psychological problems of substance 326 use in Korean adolescents. BMC Public Health 2015; 16: 79. 
10. Leatherdale, S.T., Rynard, V. A cross-sectional examination of modifiable risk factors for chronic disease among a nationally representative sample of youth: are Canadian students graduating high school with a failing grade for health? BMC Public Health 2013; 13: 569.

11. Gulliver A, Farrer L, Chan JK, Tait RJ, Bennett K, Calear AL, et al. Technology-based interventions for tobacco and other drug use in university and college students: a systematic review and meta-analysis. Addiction Science \& Clinical Practice 2015; 10: 5.

12. Masoudi Boroujeni D, Baghianimoghadam MH, Sharifirad G, Fallahzadeh H. Evaluation of Preventive Behaviors of Addiction Based on Health Belief Model (HBM) among Male High School Students in Boroujen, Iran. Journal of Health Science Research 2012; 8(2): 237 To 246 13. Glanz K, Rimer K, Barbara K. Health behavior and health education theory Research and Practice. 2008. $4^{\text {th }}$ edition. USA,CA: Bass J ;.

14.Ruiz-Moral R, Palenzuela-Paniagua S, Magallón-Botaya R. et al. Opinions and beliefs held by Spanish teenagers regarding tobacco and alcohol consumption: a descriptive study. BMC Public Health 2015; 15: 61.

15. Nunnally JC, Bernstein IH. Psychometric Theory: 4th Ed. New York: McGraw-Hill, 1994.

16. Harrington D. Confirmatory factor analysis. New York: Oxford University Press, 2009.

17. Litwin MS. How to measure survey reliability and validity? London: Sage Publications; 1995.

18. Hsieh H-F, Shannon SE. Three approaches to qualitative content analysis. Qualitative health research 2005;15(9): 1277-1288.

19. Panahi R, Ramezankhani A, Tavousi M, Niknami S. Adding health literacy to the health belief model: Effectiveness of an educational intervention on smoking preventive behaviors among university students. Iranian Red Crescent Medical Journal 2018; $20: 2$.

20. Mazloomy Mahmoodabad SS, Khoshab S, SohrabiVafa F, Fallahzadeh F, YassiniArdekani SM. The Effect of Health Education based on Health Belief Model on Preventive Actions of 
352 Synthetic Substances Dependence in Male Students of Kerman, Iran. Social Behavior Research 353 \& Health 2017 ; 1(2): 100-107. 
Table 1: The HBM-SAPQA after Exploratory Factor Analysis

\begin{tabular}{|c|c|c|c|c|c|c|}
\hline \multirow[b]{2}{*}{ Perceived benefits } & \multirow[b]{2}{*}{ Questions } & \multicolumn{5}{|l|}{ Component } \\
\hline & & Perceived severity & Perceived susceptibility & Perceived benefits & $\begin{array}{l}\text { Perceived } \\
\text { efficacy }\end{array}$ & Perceived barriers \\
\hline Q 1 & I see addiction prevention as a value for students. & 0.044 & -0.031 & 0.454 & 0.146 & 0.192 \\
\hline Q 2 & $\begin{array}{l}\text { I see addiction prevention as promoting the cure of } \\
\text { AIDS and hepatitis. }\end{array}$ & 0.121 & -0.088 & 0.639 & -0.018 & 0.002 \\
\hline Q 3 & $\begin{array}{l}\text { I consider addiction prevention to be less expensive } \\
\text { than cure. }\end{array}$ & 0.160 & 0.059 & 0.313 & 0.001 & -0.161 \\
\hline Q 4 & $\begin{array}{l}\text { I addiction prevention behavior by students can be } \\
\text { passed on to their families and friends }\end{array}$ & 0.189 & 0.041 & 0.630 & 0.112 & 0.052 \\
\hline Q 5 & $\begin{array}{l}\text { addiction prevention behavior could increase social } \\
\text { and economic efficiency in young people. }\end{array}$ & -0.059 & 0.090 & 0.655 & 0.087 & -0.047 \\
\hline Q 6 & $\begin{array}{l}\text { Doing addiction prevention behaviors could } \\
\text { prevents oneself from getting involved in addiction } \\
\text { unawareness }\end{array}$ & 0.030 & 0.139 & 0.596 & 0.038 & -0.028 \\
\hline Q 7 & $\begin{array}{l}\text { Addiction prevention behaviors could prevent from } \\
\text { mental disorders and depression }\end{array}$ & -0.104 & 0.080 & 0.580 & 0.100 & 0.097 \\
\hline Q 8 & $\begin{array}{l}\text { Addiction prevention could prevent economic } \\
\text { pressure on individuals and society }\end{array}$ & 0.063 & 0.138 & 0.662 & -0.035 & -0.013 \\
\hline Q 9 & $\begin{array}{l}\text { Addiction prevention behaviors could prevent } \\
\text { divorce, dismissal, and other social problems. }\end{array}$ & 0.076 & 0.221 & 0.518 & -0.062 & 0.058 \\
\hline \multicolumn{7}{|c|}{\begin{tabular}{|l|l|} 
Perceived barrier & \\
\end{tabular}} \\
\hline Q 1 & $\begin{array}{l}\text { Saying NO against the suggestion of my friends to } \\
\text { take substances is difficult for me }\end{array}$ & 0.021 & 0.102 & -0.001 & 0.059 & 0.519 \\
\hline Q 2 & $\begin{array}{l}\text { My families awareness of addiction prevention } \\
\text { behaviors is insufficient }\end{array}$ & 0.007 & -0.008 & 0.145 & 0.142 & 0.536 \\
\hline Q 3 & $\begin{array}{l}\text { The awareness of principals and teachers about } \\
\text { addiction prevention is insufficient }\end{array}$ & 0.104 & 0.068 & -0.096 & 0.187 & 0.503 \\
\hline Q 4 & In my country, substances are available easily & -0.049 & -0.008 & -0.015 & -0.035 & 0.566 \\
\hline Q 5 & $\begin{array}{l}\begin{array}{l}\text { Addiction prevention behavior takes time and } \\
\text { expense }\end{array} \\
\text { a }\end{array}$ & -0.023 & 0.121 & 0.146 & -0.099 & 0.521 \\
\hline Q 6 & $\begin{array}{l}\text { There are few experts and people who know how to } \\
\text { prevent addiction }\end{array}$ & -0.280 & -0.092 & 0.004 & -0.099 & 0.447 \\
\hline Q 7 & $\begin{array}{l}\text { Talking about addiction is hard and embarrassing } \\
\text { for me. }\end{array}$ & -0.344 & -0.116 & 0.014 & -0.268 & 0.360 \\
\hline Q 8 & Addiction prevention behavior costs a lot. & -0.262 & 0.123 & -0.081 & -0.070 & 0.395 \\
\hline Q9 & $\begin{array}{l}\text { Asking for help from the families to do addiction } \\
\text { prevention behavior is scary and difficult. }\end{array}$ & -0.360 & 0.147 & 0.051 & -0.037 & 0.260 \\
\hline \multicolumn{7}{|l|}{$\begin{array}{l}\text { Perceived } \\
\text { severity }\end{array}$} \\
\hline Q 1 & $\begin{array}{l}\text { Substance addiction wastes family and community } \\
\text { spending }\end{array}$ & 0.398 & 0.202 & 0.048 & 0.136 & -0.286 \\
\hline Q 2 & $\begin{array}{l}\text { Failure to prevent addiction can lead to serious } \\
\text { illness and reduced life expectancy }\end{array}$ & 0.553 & 0.200 & 0.010 & -0.014 & -0.101 \\
\hline Q 3 & $\begin{array}{l}\text { Substance use increases the risk of death in young } \\
\text { people. }\end{array}$ & 0.673 & 0.172 & 0.212 & -0.008 & -0.056 \\
\hline Q 4 & $\begin{array}{l}\text { Failure to prevent addiction can lead to increased } \\
\text { violence, neurological distress as well as reduced } \\
\text { academic achievement. }\end{array}$ & 0.649 & 0.083 & 0.147 & 0.116 & -0.022 \\
\hline Q 5 & $\begin{array}{l}\text { Non-addiction prevention reduces social popularity } \\
\text { and credibility }\end{array}$ & 0.496 & 0.082 & -0.071 & -0.095 & -0.247 \\
\hline Q 6 & Taking substances even for once is dangerous & 0.603 & -0.028 & 0.116 & 0.008 & 0.115 \\
\hline Q 7 & Substance use changes your life plan dangerously. & 0.751 & 0.108 & 0.027 & 0.035 & 0.039 \\
\hline Q 8 & Substance use reduces a person's vitality & 0.730 & 0.051 & 0.067 & 0.049 & 0.026 \\
\hline \multicolumn{7}{|l|}{$\begin{array}{l}\text { Perceived } \\
\text { susceptibility }\end{array}$} \\
\hline Q 1 & $\begin{array}{l}\text { Young people as the strongest group are not at risk } \\
\text { for addiction. }\end{array}$ & -0.003 & 0.591 & -0.046 & 0.053 & -0.019 \\
\hline Q 2 & $\begin{array}{l}\text { Since my friends and relatives are not addicted, I } \\
\text { am not susceptible to addiction. }\end{array}$ & 0.234 & 0.710 & 0.135 & -0.031 & 0.017 \\
\hline Q 3 & Associating with addicted people is not dangerous & -0.153 & 0.716 & 0.020 & 0.024 & 0.070 \\
\hline Q 4 & Entertainment is not addictive for teens & 0.136 & 0.656 & 0.150 & -0.059 & -0.040 \\
\hline Q 5 & $\begin{array}{l}\text { My high physical endurance alone is enough to } \\
\text { prevent addiction }\end{array}$ & 0.096 & 0.466 & 0.133 & -0.088 & 0.139 \\
\hline Q 6 & $\begin{array}{l}\text { Substance could use to pain relief without addiction } \\
\text { risk }\end{array}$ & 0.280 & 0.399 & 0.091 & 0.197 & 0.130 \\
\hline Q 7 & $\begin{array}{l}\text { It is best to take substances to reduce mental health } \\
\text { problems, anxiety and depression. }\end{array}$ & 0.275 & 0.628 & 0.070 & 0.102 & 0.050 \\
\hline Q 8 & $\begin{array}{l}\text { Attendance at parties where addictive substances } \\
\text { are consumed is not dangerous }\end{array}$ & 0.022 & 0.532 & 0.129 & 0.087 & 0.020 \\
\hline \multicolumn{7}{|l|}{$\begin{array}{l}\text { Perceived } \\
\text { efficacy }\end{array}$} \\
\hline Q 1 & $\begin{array}{l}\text { How confident you are that you are able to } \\
\text { withstand the pressure of friends for using } \\
\text { substances? }\end{array}$ & 0.120 & 0.034 & 0.078 & 0.764 & 0.030 \\
\hline Q 2 & $\begin{array}{l}\text { How confident you are that you can resist against } \\
\text { using substances when facing with social problems? }\end{array}$ & .002 & -0.030 & 0.050 & 0.751 & 0.092 \\
\hline Q 3 & $\begin{array}{l}\text { How confident you are that you do not use } \\
\text { substances even once for fun. }\end{array}$ & 0.042 & 0.130 & 0.050 & 0.725 & -0.040 \\
\hline Q 4 & $\begin{array}{l}\text { How confident you are that you do not attend in } \\
\text { parties with substances use in which? }\end{array}$ & 0.011 & -0.006 & 0.128 & 0.817 & -0.034 \\
\hline
\end{tabular}


$354 \quad$ Additional files

355 Additional file 1: HBM-SAPQA (PDF) 


\section{Supplementary Files}

This is a list of supplementary files associated with this preprint. Click to download.

- ADDITIONALFILE.1.pdf 